\title{
Comparison of fixatives and fixation time for PCR detection of Mycobacterium in zebrafish Danio rerio
}

\author{
Tracy S. Peterson ${ }^{1, *}$, Michael L. Kent ${ }^{1,2}$, Jayde A. Ferguson ${ }^{4}$, Virginia G. Watral ${ }^{1}$, \\ Christopher M. Whipps ${ }^{3}$
}

\author{
${ }^{1}$ Department of Microbiology, Oregon State University, Corvallis, Oregon 97331, USA \\ ${ }^{2}$ Department of Biomedical Sciences, Oregon State University, Corvallis, Oregon 97331, USA \\ ${ }^{3}$ Department of Environmental Science and Forestry, State University of New York College of Environmental \\ Science and Forestry, SUNY-ESF, 1 Forestry Drive, Syracuse, New York 13210, USA
}

${ }^{4}$ Alaska Department of Fish and Game, Commercial Fisheries Division, Pathology Laboratory, Anchorage, Alaska 99518, USA

\begin{abstract}
Mycobacteriosis is a common disease of laboratory zebrafish Danio rerio. Different infection patterns occur in zebrafish depending on mycobacterial species. Mycobacterium marinum and $M$. haemophilum produce virulent infections associated with high mortality, whereas $M$. chelonae is more widespread and is not associated with high mortality. Identification of mycobacterial infections to the species level provides important information for making management decisions. Observation of acid-fast bacilli in histological sections or tissue imprints is the most common diagnostic method for mycobacteriosis in fish, but only allows for diagnosis to the genus level. Mycobacterial culture followed by molecular or biochemical identification is the traditional approach, but DNA of diagnostic value can also be retrieved from paraffin blocks. Here we investigated the type of fixative, time in fixative before processing, species of mycobacteria, and severity of infection as parameters to determine whether the hsp gene PCR assay (primer set HS5F/hsp667R) could detect and amplify mycobacterial DNA from paraffin-embedded zebrafish. Whole zebrafish were experimentally infected with either $M$. chelonae or $M$. marinum, and then preserved in 10\% neutral buffered formalin or Dietrich's fixative for 3, 7, 21, and $45 \mathrm{~d}$. Subsequently, fish were evaluated by hematoxylin and eosin and Fite's acid-fast stains to detect mycobacteria within granulomatous lesions. The PCR assay was quite effective and obtained PCR product from 75 and $88 \%$ of the $M$. chelonae- and $M$. marinum-infected fish, respectively. Fixative type, time in fixative, and mycobacterial species showed no statistical relationship with the efficacy of the PCR test.
\end{abstract}

KEY WORDS: PCR · Mycobacterium marinum • Mycobacterium haemophilum $\cdot 10 \%$ NBF Formalin · Dietrich's · Zebrafish · Infection severity · Diagnostics

Resale or republication not permitted without written consent of the publisher

\section{INTRODUCTION}

Piscine mycobacteriosis is a well-characterized disease, with several mycobacterial species infecting multiple genera and species of fish (Decostere et al. 2004, Lewis \& Chinabut 2011). Zebrafish Danio rerio are now a widely used vertebrate animal model in biomedical research (Lele \& Krone 1996, Dooley \&
Zon 2000, Grunwald \& Eisen 2002, Rubinstein 2003, Aleström et al. 2006, Allen \& Neely 2010) with an ever-increasing number of academic and private laboratories using zebrafish. Since the emergence of the zebrafish as a pre-eminent animal model, there has been a corresponding interest in diseases that may occur in this species within a laboratory setting. The Zebrafish International Resource Center (ZIRC) 
in Eugene, Oregon, USA (http://zebrafish.org/zirc/ home/guide.php), has provided a diagnostic service to the zebrafish research community since 2000. Mycobacteriosis, based on observation of acid-fast bacteria in histological sections, has been detected at $41 \%$ of submitting facilities in about 150 cases with over 500 fish (http://zebrafish.org/zirc/health/ diseaseManual.php).

Several species of Mycobacterium have been reported to cause disease in zebrafish, including $M$. chelonae (Astrofsky et al. 2000, Kent et al. 2004, Murray et al. 2011), $M$. peregrinum (Kent et al. 2004), $M$. haemophilum (Whipps et al. 2007, 2012), and $M$. marinum (Ostland et al. 2008). Based on observations reported in diagnostic cases (Astrofsky et al. 2000, Kent et al. 2004, Whipps et al. 2008, 2012, Murray et al. 2011) and laboratory transmission studies (Watral \& Kent 2007, Whipps et al. 2007, Ostlander al. 2008), the severity of mycobacteriosis is usually related to the Mycobacterium species causing the infection. $M$. chelonae is relatively widespread and causes chronic infections but minimal mortalities (Whipps et al. 2008, Murray et al. 2011). There have been 6 outbreaks of $M$. haemophilum, which caused severe infections with high but chronic mortality (Whipps et al. 2007). M. marinum is uncommonly isolated from cases of mycobacteriosis in zebrafish, but when infection occurs it is associated with acute disease and high mortalities (Watral \& Kent 2007, Ostland et al. 2008).

Histology is the primary diagnostic method that we use with zebrafish, but diagnosis of mycobacterial infections by histology only allows for identification of the bacteria to the genus level. Of the over 150 cases diagnosed histologically by ZIRC, identification of the bacteria to the species level using culture or molecular methods has been achieved in fewer than 20 cases (Watral \& Kent 2007, Whipps et al. 2007, 2008, 2012). Mycobacterial DNA can be amplified from human and animal (including fish) tissues from paraffin blocks (Ghossein et al. 1992, Miller et al. 1997, Marchetti et al. 1998, Zink \& Nerlich 2004, Pourahmad et al. 2009a). Efforts to develop PCR assays that would reduce the time required for diagnosis as well as increase both the specificity and sensitivity of detecting mycobacteria in formalin-fixed, paraffin-embedded tissues have been ongoing, and are mostly focused on human mycobacteriosis (Pao et al. 1988, 1990, Fiallo et al. 1992, Hardman et al. 1996, Rish et al. 1996, Osaki et al. 1997, Salian et al. 1998, Whittington et al. 1999, Singh et al. 2000, Baba et al. 2008) and to a lesser extent, mycobacterial infections of animals including fish (Gyimesi et al. 1999, Putti- naowarat et al. 2002, Pourahmad 2009a,b). Results have been mixed with this approach, and time in fixative before processing into paraffin blocks appears to be an important factor for successfully obtaining mycobacterial DNA from tissues (Tokuda et al. 1990, Greer et al. 1991).

Fixative formulations, especially those containing acids or alcohol at various concentrations, can also influence the ability to retrieve DNA (Eltoum et al. 2001). Most human and veterinary laboratories use $10 \%$ neutral buffered formalin as a fixative, which is also used for preservation of zebrafish and tissues from other fishes (Ferguson 2006, Harper \& Lawrence 2011). However, zebrafish have been traditionally preserved in Dietrich's fixative, a mixture of chemicals that contains acetic acid and $95 \%$ alcohol in addition to formaldehyde. The ZIRC zebrafish diagnostic program is largely based on histologic evaluation of whole fish specimens; however, there is a need to identify mycobacterial infections to the species level in order to allow for informed management of these infections. Subsequently, we developed a PCR test for retrieval of mycobacterial DNA and evaluated the influence of time and fixative (either $10 \%$ neutral buffered formalin or Dietrich's) on the ability to recover DNA for PCR assays. This was achieved by experimentally infecting zebrafish with either Mycobacterium chelonae or M. marinum, and preserving the infected fish in both fixatives for various time points up to $45 \mathrm{~d}$.

\section{MATERIALS AND METHODS}

Mycobacterial cultures used for inoculation were prepared in the following manner. Stock cultures from the Kent laboratory reference collection of Mycobacterium marinum OSU 214 (M. marinum) and $M$. chelonae H1E2 ( $M$. chelonae) were incubated on Columbia colistin and nalidixic acid 5\% sheep blood and Middlebrook 7H10 agar (Remel) for $14 \mathrm{~d}$ at a temperature of $28^{\circ} \mathrm{C}$. Fresh culture material from agar plates was loop-inoculated into sterile phosphate-buffered saline (PBS), washed 3 times to eliminate carry-over of antimicrobial chemicals from the agar plates and then adjusted in sterile PBS to an optical density of 1.0 based on the MacFarlane scale, yielding an approximate dose of $1 \times 10^{6}$ bacteria per $25 \mu \mathrm{l}$ for the final injection amount.

AB strain adult zebrafish of mixed sex were obtained from the Sinnhuber Aquatic Research Laboratory at Oregon State University as experimental animals. Fish were housed in a biosafety- 
level 2 laboratory and maintained for $12 \mathrm{wk}$ after inoculation, allowing for progression of infection, in triplicate flow-through tanks at 25 to $27^{\circ} \mathrm{C}$ with supplemental aeration and a 14:10 h light:dark photoperiod. For inoculation with Mycobacterium marinum and $M$. chelonae, fish were anesthetized with $100 \mathrm{mg} \mathrm{l}^{-1}$ tricaine methanosulfonate (MS-222) and then aseptically given intraperitoneal injections in the right flank, to avoid accidentally lancing the spleen, with $25 \mu \mathrm{l}$ of either sterile PBS (sham-inoculated control group) or the prepared $M$. marinum and $M$. chelonae inocula. At the end of $12 \mathrm{wk}$, moribund fish and all surviving fish were euthanized by overdose of MS-222, the operculae were removed, and fish were incised along the ventrum in order to expose viscera to the fixative solutions, then immediately placed into $15 \mathrm{ml}$ of either Dietrich's fixative or $10 \%$ neutral buffered formalin (NBF). Fish were held in Dietrich's fixative or $10 \%$ NBF for 3, 7, 21, and $45 \mathrm{~d}$ (Table 1).

\section{Histology and PCR}

Decalcification was performed on the fixed zebrafish samples as follows. Fish preserved in Dietrich's fixative were decalcified in $5 \%$ trichloroacetic acid overnight (following the ZIRC protocol), while fish preserved in $10 \% \mathrm{NBF}$ were placed in CalExII (Fisher Scientific) for $48 \mathrm{~h}$. After decalcification and rinsing for $30 \mathrm{~min}$ with de-ionized water, all fish were transferred to $70 \%$ ethanol and held no longer than $48 \mathrm{~h}$ before processing. Following fixation, zebrafish were processed for paraffin embedding by routine procedures. Sections examined for histology were cut at $5 \mu \mathrm{m}$ and stained with hematoxylin and eosin as well as Fite's acid-fast stain for detection of acidfast bacilli (Luna 1968).

PCR scrolls were made from dry tissue sections cut from blocks at $5 \mu \mathrm{m}$ thickness after decontamination and prepared for DNA extraction in the following manner. Prior to sectioning the scrolls, each tissue block was wiped down with 1 DNA AWAYTM wipe (Molecular BioProducts), then faced with a new microtome blade. The block face was wiped with a fresh DNA AWAYTM wipe, the microtome blade changed, and 12 sections $(5 \mu \mathrm{m})$ cut in a scroll. Two scrolls, handled with clean wooden toothpicks, were placed into a sterile, pre-labeled $1.5 \mathrm{ml}$ microfuge tube. Microtome blades were discarded after cutting scrolls for each tissue block, in order to avoid cross-contamination. The entire microtome was then wiped down with xylene (to
Table 1. Danio rerio infected with Mycobacterium spp. Proportion of PCR positives (primer set HS5F/hsp667R) and mean granuloma intensity in paraffin-embedded zebrafish. Fish were preserved in either $10 \%$ neutral buffered formalin (NBF) or Dietrich's fixative for various times (days, in parentheses) before processing. There was no statistical significance in prevalence between mycobacterial species, fixatives, or duration of fixation (all $\mathrm{p} \geq 0.3$, Fisher's exact test). Granulomas fish ${ }^{-1}$ are reported as the mean for the total group, and the mean of PCR negative and positive fish

\begin{tabular}{|c|c|c|c|c|}
\hline \multirow[t]{2}{*}{ Group } & \multirow{2}{*}{$\begin{array}{l}\mathrm{PCR}+\mathrm{ve} / \\
\text { no. tested }\end{array}$} & \multicolumn{3}{|c|}{ _ Granulomas fish ${ }^{-1}$} \\
\hline & & Total & PCR-ve & PCR+ve \\
\hline \multicolumn{5}{|l|}{ M. chelonae } \\
\hline $\operatorname{NBF}(3 \mathrm{~d})$ & $5 / 5$ & 14.4 & - & - \\
\hline $\operatorname{NBF}(7 \mathrm{~d})$ & $4 / 5$ & 6.2 & 9.0 & 5.5 \\
\hline $\operatorname{NBF}(21 d)$ & $3 / 5$ & 15.4 & 19.5 & 12.7 \\
\hline $\operatorname{NBF}(45 d)$ & $1 / 5$ & 5.6 & 5.5 & 6.0 \\
\hline Dietrich's (3 d) & $4 / 5$ & 8.4 & 14.0 & 7.0 \\
\hline Dietrich's (7 d) & $4 / 5$ & 8.0 & 1.0 & 9.75 \\
\hline Dietrich's (21 d) & $4 / 5$ & 11.8 & 15.0 & 11.0 \\
\hline Dietrich's (45 d) & $5 / 5$ & 8.6 & - & - \\
\hline \multicolumn{5}{|l|}{ M. marinum } \\
\hline NBF (3 d) & $5 / 5$ & 14.6 & - & - \\
\hline $\operatorname{NBF}(7 \mathrm{~d})$ & $5 / 5$ & 35.0 & - & - \\
\hline $\mathrm{NBF}(21 \mathrm{~d})$ & $5 / 5$ & 38.0 & - & - \\
\hline NBF $(45 \mathrm{~d})$ & $5 / 5$ & 20.2 & - & - \\
\hline Dietrich's (3 d) & $4 / 5$ & 36.2 & 26.0 & 38.75 \\
\hline Dietrich's (7d) & $4 / 5$ & 33.0 & 25.0 & 35.0 \\
\hline Dietrich's (21 d) & $4 / 5$ & 20.8 & 16.0 & 22.0 \\
\hline Dietrich's (45 d) & $3 / 5$ & 29.0 & 22.5 & 33.3 \\
\hline
\end{tabular}

remove excess paraffin waste) and 100\% ethanol, allowed to air dry, and then wiped down with a DNA AWAYTM wipe and air-dried. Gloves were changed between microtome cleaning, blade changes, and tissue block handling. After every 5 blocks, scrolls were obtained from a block containing a negative zebrafish from the Sinnhuber Aquatic Research Laboratory specific pathogen-free colony. All tissue blocks and PCR scrolls were prepared in an identical manner.

Paraffin-embedded tissue sections were washed twice with $1.2 \mathrm{ml}$ of xylene and then twice with the same volume of $100 \%$ ethanol, which followed the recommended protocol for the Qiagen DNeasy Blood \& Tissue Kit. The tissue pellet was suspended in $375 \mu$ of ATL buffer, and Antifoam A (SigmaAldrich) was added to a final concentration of $1 \%$. This was transferred to a $0.5 \mathrm{ml}$ screw cap tube containing $300 \mu \mathrm{l}$ of $0.1 \mathrm{~mm}$ Zirconia/Silica Beads (BioSpec Products) and placed on a Mini-BeadBeater 16 (BioSpec Products) for 3 min. The bead beating step was incorporated, as preliminary studies showed that this yielded more positive results. Thirty $\mu$ of $20 \mathrm{mg} \mathrm{ml}^{-1}$ Proteinase K were added to this disrupted 
tissue and digested overnight in a $45^{\circ} \mathrm{C}$ water bath. The sample was centrifuged, and then $200 \mu$ l were removed and DNA was extracted following the manufacturer's instructions. PCR was carried out with primers HS5F (GTC ATC ACC GTC GAG GAG) and hsp667R (Selvaraju et al. 2005), yielding a 156 bp product of hsp65 sequence. The new primer HS5F was designed to be a Mycobacterium-general primer based on sequence alignments of approximately 80 representative sequences. The primer locations are as follows, based on the reference sequence from Mycobacterium leprae (GenBank accession M14341): HS5F (655-672) and hsp667R (792-810). The short fragment size of the target region was used to maximize efficiency of amplification of the potentially low quality and cross-linked DNA in preserved specimens. Amplifications were performed on a $\mathrm{C} 1000^{\mathrm{TM}}$ Thermal Cycler (BioRad Laboratories) with initial denaturation at $95^{\circ} \mathrm{C}$ for $3 \mathrm{~min}$, followed by 35 cycles of $94^{\circ} \mathrm{C}$ for $30 \mathrm{~s}, 54^{\circ} \mathrm{C}$ for $45 \mathrm{~s}, 68^{\circ} \mathrm{C}$ for $60 \mathrm{~s}$, and a final extension at $68^{\circ} \mathrm{C}$ for $7 \mathrm{~min}$. Product amplification was evaluated by observation on a $2 \%$ agarose gel. To confirm the specificity of the PCR reactions, products from a subset of 3 positives each of $M$. chelonae and $M$. marinum samples were sequenced. Amplification products were purified using the E.Z.N.A. Cycle Pure Kit (Omega Bio-Tek), and direct sequencing was performed using primer HS5F on the ABI BigDye Terminator Cycle Sequencing Ready Reaction Kit v3.1, using the ABI3730xl Genetic Analyzer (Applied Biosystems).

\section{Severity of infection}

Individual infected fish were scored as light or heavy infections by enumerating granulomas containing acid-fast bacteria in 2 whole-body sagittal sections per fish per slide. For both Mycobacterium marinum and $M$. chelonae, light and heavy infections were classified as 1-6 and >6 granulomas, respectively.

\section{Statistics}

All statistical analyses were conducted with $\mathrm{R}$ version 2.7.2 (R Development Core Team). Significance was set at $\mathrm{p} \leq 0.05$, and $\mathrm{p}$-values are 2-tailed. Differences in PCR prevalence between Mycobacterium species, fixative types, and fixation duration were tested with Fisher's exact test. A generalized linear regression model was used to evaluate the influence that fish sex, Mycobacterium species, fixative type, fixation time, and number of granulomas (indicating level of infection) detected by histology had on the ability of the PCR (primer set HS5F/hsp667R) to successfully detect Mycobacterium DNA. Logistic regression was the most appropriate technique to evaluate these effects because the response of PCR detection is a binary variable. This model had a logit link function, and an interaction effect of fixative and fixation time was explored. The likelihood ratio test was used to determine how well the model fit the data compared to the null model of just the intercept. Individual variables and combinations thereof were also tested using a backwards elimination technique.

\section{RESULTS}

DNA was successfully recovered from a large number of the histology-positive samples, irrespective of total fixation time, type of fixative, or Mycobacterium spp. (Table 1). There was no significant interaction effect of fixative and fixation time ( $p>0.99)$, so this variable was removed, and the resulting model that contained the variables of interest did not fit the data as well as the null model ( $\mathrm{p}=0.37 ; \chi^{2}=7.5$, $\mathrm{df}=7$ ), meaning that none of these variables explained the variation in the detection of mycobacterial DNA by PCR. Similar results were obtained by evaluating individual variables and combinations thereof. Fixation time of $45 \mathrm{~d}$ showed a trend towards fewer PCR positives, and 1 of the 4 groups at this time period ( $M$. chelonae in $10 \% \mathrm{NBF}$ ) had only 1 of 5 positive samples. Although this time in fixative was not a statistically significant influence, it was suggestive of having an effect $(p=0.08)$. None of the histologynegative control fish that were included throughout the evaluations was positive by PCR. Sequencing of 3 M. marinum and $3 \mathrm{M}$. chelonae PCR-positive samples confirmed their identity.

Severity of infection was also evaluated as an explanatory variable. Mortality occurred in the Mycobacterium marinum group, and overall these fish exhibited about 3 times the number of granulomas containing acid-fast bacteria than the $M$. chelonae-infected fish (29.6 versus 9.4 granulomas fish $^{-1}$, respectively) that were positive by PCR (Table 1). The M. chelonae groups yielded fewer positive fish by PCR, but there was no significant relationship with PCR compared to either Mycobacterium species or number of granulomas fish ${ }^{-1}$. There was also no significant difference between fixative types. 


\section{DISCUSSION}

Evaluation of DNA sequences has become a cornerstone in bacterial species identification. This is certainly the case for Mycobacterium species, as they are often fastidious, grow slowly, and typically provide few culture-specific or biochemical traits by conventional methods that facilitate species-level identification (Daniel 1990, Cousins et al. 1992). It is often more useful to obtain sequences for diagnoses directly from infected tissues, particularly for $\mathrm{Myco}$ bacterium species that are slow growing or require specialized media. This approach has been used to diagnose mycobacterial infections directly from frozen or freshly infected fish (Whipps et al. 2003, 2007, Kaattari et al. 2005, Poort et al. 2006). Often only formalin-preserved tissues embedded in paraffin are available, which has led to attempts to obtain mycobacterial DNA from paraffin-embedded tissues following observation of either chronic lesions (i.e. granulomas) or the presence of acid-fast bacteria in tissues that are indicative of mycobacterial infection (Ghossein et al. 1992, Miller et al. 1997, Marchetti et al. 1998, Zink \& Nerlich 2004, Pourahmad et al. 2009a,b).

Fixatives used to preserve tissues (regardless of whether they are coagulant or non-coagulant fixatives) and the total time the tissues are held in a fixative can result in degradation of DNA and RNA within tissues (Dubeau et al. 1986, Fiallo et al. 1992, Foss et al. 1994). Exposure of mycobacterial DNA to formalin causes production of Schiff bases on the free amino groups of nucleotides (Fraenkel-Conrat 1954, Dubeau et al. 1986), and subsequent crosslinking between tissue proteins and DNA (Jackson \& Chalkey 1974). Therefore, time in formalin is considered to be among the most important criteria for successful DNA retrieval and PCR amplification following tissue processing for histology (Ben-Ezra et al. 1991, Greer et al. 1991). Once the tissues are embedded in paraffin wax, this degradation process is slowed, and subsequent amplification of short DNA sequences is successful (Shibata et al. 1988). Fish are often preserved at a research laboratory, aquaculture facility, or in the field, and then shipped many days later to another laboratory for histology processing. Hence, there was particular interest in the effects of time in fixative. Positive results were consistently obtained with fish held in fixative up to $21 \mathrm{~d}$, and the same occurred at $45 \mathrm{~d}$ with the exception of 1 group. This positive result at the later time points was somewhat surprising. Mycobacterium spp. has a unique, waxy cell wall comprised of lipids and fatty acids
(Kolattukudy et al. 1997), which may exclude aldehydes to some extent. Perhaps this characteristic plays a role in preserving DNA more than in non-acid-fast bacteria exposed to formalin-based fixatives.

Dietrich's, Davidson's, and Bouin's fixatives are commonly used with fish tissues. These contain acid and alcohol, both of which cause denaturation and coagulation of proteins and nucleic acids within tissue specimens by dehydration and disruption of electrostatic and hydrogen bonding (Fournie et al. 2000, Eltoum et al. 2001). Tissues preserved in Bouin's solution (which contains both picric and acetic acid) are particularly problematic for DNA retrieval (Greer et al. 1991). Interestingly, there was no reduction in positive samples with Dietrich's compared to $10 \%$ buffered formalin.

Some samples were negative in both fixatives at some of the early time points. The inability to retrieve DNA logically would be influenced by the amount of bacterial DNA. Incorporation of bead beating enhances retrieval of DNA from formalin-preserved samples to liberate more DNA (Tripathi \& Stevenson 2012). This was included with the PCR protocol because from previous experiences it was found to consistently yield more positive results with PCR from paraffin-embedded tissues. Nevertheless, there was no significance in the ability to detect mycobacterial DNA based on severity of infection. The results were similar to previous transmission studies regarding the virulence of Mycobacterium chelonae compared to $M$. marinum in zebrafish (Watral \& Kent 2007, Ostland et al. 2008, Whipps et al. 2008). The $M$. marinum isolate was highly virulent, and several fish became moribund or died over the $8 \mathrm{wk}$ period, and these fish were included in $45 \mathrm{~d}$ samples. In contrast, all fish injected with $M$. chelonae became infected, but none exhibited morbidity or mortality. The $M$. marinum-infected fish had 3 times the number of granulomas with acid-fast bacteria, but the recovery and detection of DNA was not different than with fish infected with $M$. chelonae.

Most zebrafish cases submitted to the ZIRC and the Kent Laboratory (OSU) for health screening and diagnosis consist of multiple fish, which are usually processed and embedded within 3 wk. Hence, even with only about 50 to $70 \%$ ability to obtain mycobacterial DNA, diagnosticians can confidently use PCR on routinely processed and paraffin-embedded zebrafish to identify these infections to the species level for many of the fish within a particular case. This is important, as the severity and distribution of these various Mycobacterium spp. found in zebrafish are quite different, and fish health managers and cli- 
nicians with species identifications in hand would be able to make more informed decisions. For example, facilities with $M$. haemophilum-infected zebrafish often euthanize infected populations, disinfect the aquaria, and repopulate (Kent et al. 2009, 2011, Whipps et al. 2012), and this approach is similarly recommended for $M$. marinum outbreaks. In contrast, $M$. chelonae infections are presently managed by cleaning tanks more frequently (Murray et al. 2011) or using different wild-type strains of zebrafish (Whipps et al. 2008). Acid-fast bacteria are frequently observed in the intestinal lumen of zebrafish, with and without infections in the visceral organs. Therefore, a concern with amplification of DNA using whole fish sections may be confusion of mycobacteria in granulomas versus intraintestinal mycobacteria that may be associated with other constitutive microbiota in the intestinal tract. A solution for the potentially confounding problem of intraintestinal bacterial contaminants would be to use histologic sections as a template to guide in the removal of specific cores from the tissue block that correspond to confirmed areas of infected organs (Sfanos et al. 2008) or, even more precisely, by using laser capture microdissection to select individual intralesional granulomas containing mycobacteria for PCR assays (Ryan et al. 2002, Zhu et al. 2003, Selva et al. 2004). Both methods would allow for accurate selection of infected tissue sites within the infected zebrafish prior to PCR analysis for mycobacterial identification and PCR primer-specific molecular identification of Mycobacterium spp.

Acknowledgements. We thank the Oregon State University Veterinary Diagnostic Laboratory for excellent histotechnical assistance. This work was supported by NIH/NCRR grants T32 RR023917, R24 RR017886 and NIEHS Center grant P30 ES000210.

\section{LITERATURE CITED}

Aleström P, Holter JL, Nourizadeh-Lillabadi R (2006) Zebrafish in functional genomics and aquatic biomedicine. Trends Biotechnol 24:15-21

Allen JP, Neely MN (2010) Trolling for the ideal model host: Zebrafish take the bait. Future Microbiol 5:563-569

Astrofsky KM, Schrenzel MD, Bullis RA, Smolowitz RM, Fox JG (2000) Diagnosis and management of atypical Mycobacterium spp. infections in established laboratory zebrafish (Brachydanio rerio) facilities. Comp Med 50: 666-672

Baba K, Pathak S, Sviland L, Langeland N and others (2008) Real-time quantitative PCR in the diagnosis of tuberculosis in formalin-fixed paraffin-embedded pleural tissue in patients from a high HIV endemic area. Diagn Mol
Pathol 17:112-117

Ben-Ezra J, Johnson DA, Rossi J, Cook N, Wu A (1991) Effect of fixation on the amplification of nucleic acids from paraffin-embedded material by the polymerase chain reaction. J Histochem Cytochem 39:351-354

Cousins DV, Wilton SD, Francis BR, Gow BL (1992) Use of polymerase chain reaction for rapid diagnosis of tuberculosis. J Clin Microbiol 30:255-258

> Daniel TM (1990) The rapid diagnosis of tuberculosis: a selective review. J Lab Clin Med 116:277-282

$>$ Decostere A, Hermans K, Haesbrouck F (2004) Piscine mycobacteriosis: a literature review covering the agent and the disease it causes in fish and humans. Vet Microbiol 99:159-166

Dooley K, Zon LI (2000) Zebrafish: a model system for the study of human disease. Curr Opin Genet Dev 10: 252-256

Dubeau L, Chandler LA, Gralow JR, Nichols PW, Jones PA (1986) Southern blot analysis of DNA extracted from formalin-fixed pathology specimens. Cancer Res 46: 2964-2969

Eltoum I, Myers RB, Grizzle WE (2001) Introduction to the theory and practice of fixation of tissues. J Histotechnol 24:173-190

Ferguson HW (2006) Systemic pathology of fish. A text and atlas of normal tissues in teleosts and their responses in disease, 2nd edn. Scotian Press, London

Fiallo P, Williams DL, Chan GP, Gillis TP (1992) Effects of fixation on polymerase chain reaction detection of Mycobacterium leprae. J Clin Microbiol 30:3095-3098

Foss RD, Guha-Thakurta N, Gutman P (1994) Effects of fixative and fixation time on the extraction and polymerase chain reaction amplification of RNA from paraffin-embedded tissue. Comparison of two housekeeping gene mRNA controls. Diagn Mol Pathol 3: 148-155

Fournie JW, Krol RM, Hawkins WE (2000) Fixation of fish tissues. In: Ostrander GK (ed) The laboratory fish. Academic Press, San Diego, CA, p 569-578

- Fraenkel-Conrat H (1954) Reaction of nucleic acids with formaldehyde. Biochim Biophys Acta 15:307-309

> Ghossein RA, Ross DG, Salomon RN, Rabson AR (1992) Rapid detection and species identification of mycobacteria in paraffin-embedded tissues by polymerase chain reaction. Diagn Mol Pathol 1:185-191

> Greer CE, Peterson SL, Kiviat NB, Manos M (1991) PCR amplification from paraffin-embedded tissues. Am J Clin Pathol 95:117-124

> Grunwald DJ, Eisen JS (2002) Headwaters of the zebrafishemergence of a new model vertebrate. Nat Rev Genet 3: 717-724

Gyimesi ZS, Stalis IH, Miller JM, Thoen CO (1999) Detection of Mycobacterium avium subspecies avium in formalin-fixed, paraffin-embedded tissues of captive exotic birds using polymerase chain reaction. J Zoo Wildl Med 30:348-353

Hardman WJ, Benian GM, Howard T, McGowan JE, Metchock B, Murtagh JJ (1996) Rapid detection of mycobacteria in inflammatory necrotizing granulomas from formalin-fixed, paraffin-embedded tissue by PCR in clinically high-risk patients with acid-fast stain and culture negative tissue biopsies. Am J Clin Pathol 106: 384-389

Harper C, Lawrence C (2011) The laboratory zebrafish. CRC Press, Boca Raton, FL 
Jackson V, Chalkey R (1974) Separation of newly synthesized nucleohistone by equilibrium centrifugation in cesium chloride. Biochemistry 13:3952-3956

Kaattari IM, Rhodes MW, Kator H, Kaattari SL (2005) Comparative analysis of mycobacterial infections in wild striped bass Morone saxatilis from Chesapeake Bay. Dis Aquat Org 67:125-132

Kent ML, Whipps CM, Matthews JL, Florio D and others (2004) Mycobacteriosis in zebrafish (Danio rerio) research facilities. Comp Biochem Physiol C Toxicol Pharmacol 138:383-390

> Kent ML, Feist SW, Harper C, Hoogstraten-Miller S and others (2009) Recommendations for control of pathogens and infectious diseases in fish research facilities. Comp Biochem Physiol C Toxicol Pharmacol 149:240-248

Kent ML, Buchner C, Watral VG, Sanders JL, LaDu J, Peterson TS, Tanguay RL (2011) Development and maintenance of a specific pathogen-free (SPF) zebrafish research facility for Pseudoloma neurophilia. Dis Aquat Org 95:73-79

Kolattukudy PE, Fernades ND, Azad AK, Fitzmaurice AM, Sirakova TD (1997) Biochemistry and molecular genetics of cell-wall lipid biosynthesis in mycobacteria. Mol Microbiol 24:263-270

Lele Z, Krone PH (1996) The zebrafish as a model system in developmental, toxicological and transgenic research Biotechnol Adv 14:57-72

Lewis S, Chinabut S (2011) Mycobacterial diseases in fish. In: Woo PTK, Bruno DW (eds) Fish diseases and disorders, Vol 3: viral, bacterial and fungal infections. CABI Wallingford, p 397-423

Luna LG (1968) Manual of histologic staining methods of the Armed Forces Institute of Pathology, 3rd edn. McGrawHill, New York, NY

> Marchetti G, Gori A, Catozzi L, Vago L and others (1998) Evaluation of PCR in detection of Mycobacterium tuberculosis from formalin-fixed, paraffin-embedded tissues: comparison of four amplification assays. J Clin Microbiol $36: 1512-1517$

> Miller J, Jenny A, Rhyan J, Saari D, Suarez D (1997) Detection of Mycobacterium bovis in formalin-fixed paraffin-embedded tissues of cattle and elk by PCR amplification of an IS6110 sequence specific for $\mathrm{Myco}$ bacterium tuberculosis complex organisms. J Vet Diagn Invest 9:244-249

> Murray KN, Bauer J, Tallen A, Matthews JL, Westerfield M, Varga ZM (2011) Characterization of asymptomatic Mycobacterium infections at the Zebrafish International Resource Center. J Am Assoc Lab Anim Sci 50:675-679

Osaki M, Adachi H, Gomyo Y, Yoshida H, Ito H (1997) Detection of mycobacterial DNA in formalin-fixed, paraffin-embedded tissue specimens by duplex polymerase chain reaction: application to histopathologic diagnosis. Mod Pathol 10:78-83

> Ostland VE, Watral V, Whipps CM, Austin FW, St-Hilaire S, Westerman ME, Kent ML (2008) Biochemical, molecular and virulence characteristics of select Mycobacterium marinum isolates in hybrid striped bass Morone chrysops $\times$ M. saxatilis and zebrafish Danio rerio. Dis Aquat Org 79:107-118

> Pao CC, Lin SS, Wu SY, Juang WM (1988) The detection of mycobacterial DNA sequences in uncultured clinical specimens with cloned Mycobacterium tuberculosis DNA as probes. Tubercle 69:27-36

> Pao CC, Benedict Yen TS, You JB, Maa JS, Fiss EH, Chang
$\mathrm{CH}$ (1990) Detection and identification of Mycobacterium tuberculosis by DNA amplification. J Clin Microbiol 28:1877-1880

Poort MJ, Whipps CM, Watral VG, Font WF, Kent ML (2006) Molecular characterization of a Mycobacterium species in non-native poeciliids in Hawaii using DNA sequences. J Fish Dis 29:181-185

Pourahmad F, Thompson KD, Adams A, Richards RH (2009a) Detection and identification of aquatic mycobacteria in formalin-fixed, paraffin-embedded fish tissues. J Fish Dis 32:409-419

Pourahmad F, Thompson KD, Adams A, Richards RH (2009b) Comparative evaluation of polymerase chain reaction-restriction enzyme analysis (PRA) and sequencing of heat shock protein 65 (hsp65) gene for identification of aquatic mycobacteria. J Microbiol Methods 76: 128-135

Puttinaowarat S, Thompson KD, Kolk A, Adams A (2002) Identification of Mycobacterium spp. isolated from snakehead, Channa striata (Fowler), and Siamese fighting fish, Betta splendens (Regan), using polymerase chain reaction-reverse cross blot hybridization (PCR$\mathrm{RCBH})$. J Fish Dis 25:235-243

Rish JA, Eisenach KD, Cave MD, Reddy MV, Gangadharam PRJ, Bates JH (1996) Polymerase chain reaction detection of Mycobacterium tuberculosis in formalin-fixed tissue. Am J Respir Crit Care Med 153:1419-1423

Rubinstein AL (2003) Zebrafish: from disease modeling to drug discovery. Curr Opin Drug Discov Devel 6:218-223

Ryan P, Bennett MW, Aarons S, Lee G and others (2002) PCR detection of Mycobacterium paratuberculosis in Crohn's disease granulomas isolated by laser capture microdissection. Gut 51:665-670

Salian NV, Rish JA, Eisenach KD, Cave MD, Bates JH (1998) Polymerase chain reaction to detect Mycobacterium tuberculosis in histologic specimens. Am J Respir Crit Care Med 158:1150-1155

Selva E, Hofman V, Berto F, Musso S and others (2004) The value of polymerase chain reaction detection of $\mathrm{Myco}$ bacterium tuberculosis in granulomas isolated by laser capture microdissection. Pathology 36:77-81

Selvaraju SB, Khan IHU, Yadav JS (2005) A new method for species identification and differentiation of $\mathrm{Myco}$ bacterium chelonae complex based on amplified hsp65 restriction analysis (AHSPRA). Mol Cell Probes 19:93-99

Sfanos KS, Suavageot J, Fedor HL, Dick JD, De Marzo AM, Isaacs WB (2008) A molecular analysis of prokaryotic and viral DNA sequences in prostate tissue from patients with prostate cancer indicates the presence of multiple and diverse microorganisms. Prostate 68:306-320

Shibata D, Martin WJ, Arnheim N (1988) Analysis of DNA sequences in forty-year-old paraffin-embedded thintissue sections: a bridge between molecular biology and classical histology. Cancer Res 48:4564-4566

Singh KK, Muralidhar M, Kumar A, Chattopadhyaya TK and others (2000) Comparison of in house polymerase chain reaction with conventional techniques for the detection of Mycobacterium tuberculosis DNA in granulomatous lymphadenopathy. J Clin Pathol 53:355-361

> Tokuda Y, Nakamura T, Satonaka K, Maeda S, Doi K, Baba S, Sugiyama T (1990) Fundamental study on the mechanism of DNA degradation in tissues fixed in formaldehyde. J Clin Pathol 43:748-751

Tripathi BN, Stevenson K (2012) Detection of Mycobacterium avium subsp. paratuberculosis in formalin-fixed, 
paraffin-embedded tissues of goats by IS900 polymerase chain reaction. Small Rumin Res 102:84-88

Watral V, Kent ML (2007) Pathogenesis of Mycobacterium spp. in zebrafish (Danio rerio) from research facilities. Comp Biochem Physiol C Toxicol Pharmacol 145: 55-60

Whipps CM, Watral VG, Kent ML (2003) Characterization of a Mycobacterium sp. in rockfish (Sebastes alutus and Sebastes reedi) using rDNA sequences. J Fish Dis 26: 241-245

Whipps, CM, Dougan ST, Kent ML (2007) Mycobacterium haemophilum infections of zebrafish (Danio rerio) in research facilities. FEMS Microbiol Lett 270:21-26

Whipps CM, Matthews JL, Kent ML (2008) Distribution and genetic characterization of Mycobacterium chelonae in

Editorial responsibility: Stephen Feist, Weymouth, UK laboratory zebrafish Danio rerio. Dis Aquat Org 82:45-54 Whipps CM, Lieggi C, Wagner R (2012) Mycobacteriosis in zebrafish colonies. ILAR J 53:95-105

Whittington RJ, Reddacliff L, Marsh I, Saunders V (1999) Detection of Mycobacterium avium subsp paratuberculosis in formalin-fixed paraffin-embedded intestinal tissue by IS 900 polymerase chain reaction. Aust Vet J 77: 392-397

> Zhu G, Xiao H, Mohan VP, Tanaka K and others (2003) Gene expression in the tuberculous granuloma: analysis by laser capture microdissection and real-time PCR. Cell Microbiol 5:445-453

> Zink AR, Nerlich AG (2004) Molecular strain identification of the Mycobacterium tuberculosis complex in archival tissue samples. J Clin Pathol 57:1185-1192

Submitted: October 30, 2012; Accepted: February 6, 2013 Proofs received from author(s): May 20, 2013 